\title{
Memoria e identidad en la literatura sefardí y mizrahi en Latinoamérica
}

\author{
Jacobo SEFAmí \\ University of California, Irvine \\ No somos tanto "el pueblo del Libro» como \\ el pueblo de la Memoria que arde sin consumirse
}

(Esther Seligson)

\section{PRESENCIA SEFARDÍ Y MIZRAHI EN LATINOAMÉRICA}

Este trabajo tiene como objetivo el examen de la literatura sefardí/mizrahi ${ }^{1}$ en América Latina; pero previamente es necesario referirse al desarrollo de esas comunidades.

\footnotetext{
${ }^{1}$ Aunque en el hebreo moderno de Israel se ha usado durante algún tiempo la expresión «bené 'edot hamiźrah» ('los descendientes de las etnias de Oriente'), en los últimos años la palabra miźrahí se ha separado de sefardí. El debate de la terminología se ha convertido en un asunto de índole político. En Israel la distinción entre sefardim y miźrahim se ha hecho cada vez más notoria. En diversas partes del mundo tanto las comunidades de sefardíes como las de los judíos oriundos de países árabes se han mantenido separadas, fundando instituciones agrupadas por zonas de origen. Aunque ya el concepto de judio oriental se venía usando desde finales del siglo XVIII y principios del XIX, realmente ha sido en la década de 1990 cuando los mismos mizrahíes en Israel han presionado para que se les reconozca una identidad separada y diferente de la sefardí. En el contexto del conflicto árabe-israelí se trata de una lucha por defender su herencia cultural árabe frente a un dogmatismo férreo que ha querido parangonar todo lo árabe con el enemigo. Vid. al respecto SHOHAT (1999) y los libros de AlCAlay $(1993,1996)$. Sin embargo, esa distinción de nomenclatura no ha ocurrido en Latinoamérica, donde las comunidades de Siria, por ejemplo, son comúnmente identificadas como sefardíes, aunque con frecuencia se designa el lugar de origen. DABBAH (1982) usa
}

Sefarad 62 (2002) págs. 143-167

(c) CSIC

ISSN 037-0894 
Las investigaciones acerca de la presencia judía en América siempre aluden a los anusim o criptojudíos como los primeros en llegar al Nuevo Mundo durante la época de la conquista y colonización ${ }^{2}$. Hoy en día los estudios acerca de las prácticas religiosas de esos judíos secretos se han incrementado considerablemente, tal vez con el incentivo de la conmemoración de los 500 años de los viajes de Colón ${ }^{3}$.

En este trabajo voy a centrarme exclusivamente en los judíos que siguieron practicando públicamente su religión y que emigraron a América Latina a finales del siglo XIX y sobre todo en las dos primeras décadas del siglo $\mathrm{XX}$, fundando instituciones comunitarias religiosas y laicas (cementerios, sinagogas, escuelas, centros sociales y deportivos, etc.).

La migración a América Latina ocurre aproximadamente a partir de 1880. Muchos judíos del Imperio Otomano (al igual que cristianos y musulmanes) comenzaron a emigrar en la última década del siglo XIX, pero sobre todo en las dos primeras del XX, debido a tres factores principales:

1) Tras la derrota del Imperio Otomano en varias guerras más o menos locales y su final después de la Primera Guerra mundial y de la caída del sultán Abdul Hamid en 1908 propiciada por los Jóvenes Turcos, el ejército intentó reclutar más soldados para fortalecerse.

la nomenclatura «judíos levantinos» para referirse a los de Siria y Líbano; y aunque Alcalay no engloba esos grupos bajo la denominación sefardí, sí concibe tal unidad bajo lo que él considera «cultura levantina». El complejo nudo que reúne grupos de diferentes lenguas se deriva, según él, de la cultura clásica andaluza del siglo $X$, que se manifiesta en una vasta región (lo que hoy es Portugal, España, sur de Francia e Italia, los países balcánicos, Grecia, Turquía, Irán, Iraq, Yemen, Siria, Líbano, Chipre, Israel/Palestina, Egipto, Marruecos, Túnez, Argelia, Libia e incluso algunas partes del Africa occidental y de la India). Alcalay también hace referencia a las múltiples formas de denominar a los judíos de esos países: asiáticos, africanos, norteafricanos, de Medio Oriente, turco-iraníes, sefardíes orientales, sefardíes, árabes, no-occidentales, orientales, o como se les solía denominar en Israel, los «descendientes de los grupos étnicos orientales» (ALCALAY 1993 pág. 37).

2 Son de sobra conocidos los procesos de la Inquisición a ciertos individuos que fueron acusados de judaizantes (por ejemplo, Luis de Carvajal el Mozo o Joseph Lumbroso); vid. GoJMAN GoLDBERG págs. 124-137 y 182-188.

3 Es interesante señalar el equívoco común en Estados Unidos de pensar que en Latinoamérica las comunidades judías, dadas las conexiones con el Imperio español, están exclusivamente formadas por anusim y/o por sefardíes. 
Bajo los regímenes anteriores, a los judíos y a otras minorías se les eximía del servicio militar mediante el pago de un impuesto. Pero la necesidad de reclutar un ejército más numeroso abolió tal excepción, con lo cual los judíos se vieron obligados a ir a los campos de batalla. Ello trajo como consecuencia que muchos de los posibles reclutas emigraran.

2) La debacle del Imperio Otomano también tuvo como consecuencia que la economía empeorara y, por ende, muchos de los judíos de escasos recursos vieron en la migración una posible solución a sus problemas económicos.

3) Después de la Primera Guerra mundial y de la instauración del control inglés y francés en la región, la incertidumbre política y la rebelión frente al poder imperial trajo consigo la inseguridad de las comunidades judías. En Siria, por ejemplo, los musulmanes se rebelaron contra el mandato francés para alcanzar la independencia en 1946.

Las oleadas migratorias variaron de un país a otro. En general, según el estudio demográfico de Sergio Della Pergola, en 1982 había 465.000 judíos en América Latina. Esa cifra representaba el $5 \%$ de los judíos de la diáspora.

La población más numerosa era la de Argentina, calculada en 233.000. Seguían después Brasil, con 100.000; México, con 35.000; Uruguay, con 30.000; y Chile y Venezuela, con 20.000. En términos de porcentaje los judíos representaban menos del 1\% (Uruguay tendría el índice más alto, con diez judíos por cada mil habitantes) de sus respectivos países. Frente a la mayoría ashkenazi originaria de Europa Oriental, la migración sefardí y mizrahi representaba una minoría calculada en un $20 \%$ del total, aunque con variantes de un país a otro ${ }^{4}$.

Según su origen hay que considerar tres grupos principales: 1) los judíos de Marruecos (en su mayor parte, sefardíes del norte, especialmente de Tetuán, Tánger y Melilla), que se concentraron en Venezuela, Argentina y Brasil (muchos también emigraron a Montreal, Canadá); 2) los judíos de Siria y Líbano, que fueron en

${ }^{4}$ No hay estadísticas muy claras acerca de la migración sefardí. LAIKIN ELKIN (1980 pág. 259) dice: «Un problema recurrente en la historiografía judía es el desbalance continuo entre las fuentes ashkenazis y las sefardíes. Se sabe mucho más acerca de las primeras que de las últimas, en parte debido a que los historiadores modernos judíos provienen por lo general del mundo ashkenazi». En relación con los judíos alepinos en América Latina, vid. también ZENNER (2000) págs. 105-125. 
su mayor parte a México, Argentina, Uruguay y Brasil, aunque hay noticia de algunas familias establecidas en Colombia, Cuba, Panamá y Guatemala; y 3) los sefardíes de Turquía, Grecia y de la zona de los Balcanes, que se asentaron en México, Argentina, Brasil, Uruguay y Chile. Hay que señalar, por otra parte, que la migración de países como Yemen, Iraq, Irán, Túnez, Argelia y Libia fue muy escasa.

En países como Argentina, Venezuela, México, Brasil y Uruguay, las diversas comunidades fundaron sus propias instituciones separadas, incluyendo una subdivisión entre los sirios de Damasco y de Alepo, particularmente en México y Argentina ${ }^{5}$.

La mayoría de la población judía se concentra en zonas urbanas. En un principio los judíos trabajaban como vendedores ambulantes, vendiendo artículos a crédito. Más tarde fueron comprando comercios en las zonas de mayor intercambio mercantil de las respectivas ciudades; otros entraron en la industria, sobre todo la textil. Aunque hay muchos profesionales, hoy en día la mayoría de los sefardíes y mizrahis se dedica al comercio y a la industria. Los diversos grupos, aunados por regiones de procedencia, se esforzaron por establecer los organismos antes mencionados, imprescindibles para el buen funcionamiento de la comunidad (sinagogas, escuelas, centros sociales de convivencia y cementerios).

El aglutinante cultural de esos grupos se basa en la familia y en la vida comunitaria; los matrimonios mixtos y la asimilación se han mantenido con índices muy bajos. Y aunque muchas de esas comunidades han publicado revistas, boletines y otros textos religiosos y laicos, no ha habido una tradición artística y literaria de consideración. En general, los escritores y artistas han surgido como entes que se automarginan para acceder a esferas ajenas al ámbito comunitario ${ }^{6}$.

\footnotetext{
${ }^{5}$ No existe ningún estudio general de las comunidades sefardíes y mizrahíes de América Latina, pero sí se han hecho trabajos que documentan la historia de comunidades de diversos países: México, BOKSER (1992) y HAMUI (1989); Panamá, DAYÁN (1986); Argentina, RUBEL (1992), MIRELMAN (1987) y GUTKOWSKI (1999); Chile, NES-El (1984) y MATUS GonZÁlEZ (1993); y Uruguay, PorZECANSKI (1986). Pueden verse también los 14 volúmenes publicados hasta la fecha de la Biblioteca Popular Sefardí del Centro de Estudios Sefardíes de Caracas: la serie incluye estudios monográficos de las comunidades de origen, dedicados a Melilla, Tetuán y Tánger en los siglos XIX y XX, y libros dedicados a la historia y presencia de la comunidad sefardí en Venezuela.

${ }^{6}$ En un artículo sobre varios escritores judíos latinoamericanos (entre ellos, Pedro Orgambide, Isaac Chocrón, Margo Glantz, Esther Seligson e Isaac Goldemberg), SOSNOWSKI (1998 pág. 1121) afirma: «La mayoría de los escritores latinoamericanos estudiados aquí no mantienen vínculos estrechos con las comunidades judías oficiales.
} 


\section{ESCRITORES SEFARDÍES/MIZRAHIS LATINOAMERICANOS}

El gran libro de América judía, compilado por Isaac Goldemberg (1998), vino a confirmar la presencia literaria de los judíos en la América Latina ${ }^{7}$. Se trata de una amplia antología de 1.236 páginas publicada por la Universidad de Puerto Rico que recoge la obra de unos 140 escritores ${ }^{8}$. La organización del volumen es un reflejo del maridaje entre lo judío y su obsesión por la letra ${ }^{9}$ y la tradición española y latinoamericana ${ }^{10}$. Además, el libro celebra de algún modo el pluralismo cultural, el mestizaje (en este caso, lo judío con lo no judío) y una multitud de estilos y géneros que abarca diferentes vertientes de la producción literaria judeo-latinoamericana.

Su adopción de ciertas normas de vida judía se produce, en general, fuera de la jurisdicción de la comunidad y de los círculos dirigentes. Estas podrían ser las condiciones previas necesarias para una percepción crítica de esos sistemas».

${ }^{7}$ La mayoría de las antologías de literatura judía latinoamericana se han publicado en la década de los noventa y sobre todo en inglés: KALECHOFSKY (1980), AgOSín (1995, 1997 y 1999), SAdow (1999) y STAVANS (1994); en español, véase FEIERSTEIN (1990). También se han publicado obras que recogen artículos sobre escritores latinoamericanos: DiANTONIO - GLICKMAN (1993), AGOSÍN (1999) y METER (2000); véase además la guía bio-bibliográfica de LOCKHART (1997). Hay trabajos (tanto antologías, como libros críticos) que versan sobre los escritores judíos de Brasil y Argentina. Ilán STAVANS es el editor de la serie «Jewish Latin America» (University of New Mexico Press), en la que se han traducido y publicado obras de escritores judíos latinoamericanos. Desde 1987 Leonardo SENKMAN publica en Jerusalén la revista Noah, fruto de la Asociación Internacional de Escritores Judíos en Lengua Hispana y Portuguesa. Muchos libros sobre judíos latinoamericanos en general incluyen secciones dedicadas a la literatura (por ejemplo, entre otros muchos, BOKSER DE LIWERANT - GOJMAN DE BACKAL [1999]). Otro organismo que se ocupa de lo mismo es LAJSA (Latin American Jewish Studies Association), que publica un boletín y celebra congresos internacionales. Es curioso que la mayoría de las publicaciones hayan surgido en Estados Unidos y no en Latinoamérica.

${ }^{8}$ Una obra como esta difícilmente habría visto la luz en Estados Unidos y me temo que va a circular poco por las librerías; sólo hay que esperar que una editorial de mayor difusión emprenda un proyecto semejante.

${ }^{9}$ La obra parte de la obsesión judía por el Libro de los Libros, el Séfer Torá o Pentateuco, que ha derivado en un laberinto de libros que intentan explicar la sacralidad y la perfección del original. Goldemberg construye su gran obra dividiéndola en trece libros que incluyen temáticas diferentes. Además, elimina los nombres de los autores en las entradas de cada selección (al final aparece una guía de fuentes), de modo que el tomo se presenta como una voz colectiva y múltiple.

10 La naturaleza descomunal del proyecto hace pensar en los excesos de la arquitectura y el decorado en las iglesias barrocas de la época colonial, o en composiciones contemporáneas que desbordan sus propios límites, como el Paradiso de José Lezama Lima, la Terra Nostra de Carlos Fuentes, o las casi 5.000 páginas de poemas de Pablo Neruda. 
Esa literatura tiene un doble matiz: por un lado, al insertarse en un plano nacional, cuestiona la cultura dominante; $y$, por otro, su vínculo con sus respectivas comunidades diaspóricas traspasa las fronteras de nación y de lengua. Hay que señalar además que también se abordan temas propios de planteamientos sociológicos actuales, como la rebelión femenina y en algunos casos la homosexualidad.

A todo ello debemos agregar que la presencia de lo sefardí y mizrahi sirve también para discutir la unidad cultural judía, a priori asumida por grupo mayoritario ashkenazi. El sefardí/mizrahi latinoamericano tiene que insistir en su diferencia, dado que hasta ahora ha tenido poca proyección tanto en los respectivos ámbitos nacionales como en los foros internacionales ${ }^{11}$.

La antología de Goldemberg me permitió confirmar que aunque minoría dentro de la minoría sí había un corpus de literatura sefardí/mizrahi con el que se podía trabajar ${ }^{12} \mathrm{y}$ en un principio concebí una lista de escritores que después he ido modificando.

Mi lista preliminar incluye: de Argentina, José Isaacson (1922), Humberto Constantini (1924-1987), Ricardo Halac (1935), Liliana Mizrahi (1943), Marcos Ricardo Barnatán (1946), Reina Roffé (1951), Ana María Shua (1951) y Mercedes Roffé (1954); de Cuba, Rafael Eli (1952) y Ruth Behar (1956); de Chile, Ester Benarí; de Guatemala, Víctor Perera (1934) y David Unger (1950); de México, Angelina Muñiz (Francia, 1936, residente en México), Vicky Nizri (1954), Myriam Moscona (1955), Esther Cohen y Rosa Nissán; de Uruguay, Teresa Porzecanski (1945); y de Venezuela, Isaac Chocrón (1930) y Sonia

${ }^{11}$ En este sentido, hay que recordar el concepto de «literatura menor», según lo han expuesto DELEUZE - GUATTARI (1978 págs. 28-44).

${ }^{12}$ La pregunta acerca de cómo delimitar la literatura sefardí/mizrahi latinoamericana es problemática. ¿Deberíamos incluir a autores que han declarado tener sangre sefardí, como por ejemplo y entre otros muchos, el escritor colombiano Alvaro Mutis)? ¿O considerar como literatura sefardí la escrita por autores no judíos, como Borges, José Emilio Pacheco, Carlos Fuentes y Homero Aridjis? ¿O, según hace AIZENBERG (1979-1982), estudiar los textos de tema sefardí escritos por ashkenazis, como Marcos Aguinis y Juan Gelman? ¿Cómo encuadrar a escritores que han evitado escribir sobre el tema sefardí/mizrahi, aunque pertenezcan a esas comunidades, como es el caso del dramaturgo argentino Ricardo Halac, cuya familia emigró de Damasco? Es cierto que las categorías restrictivas pueden llegar a asfixiar, pero por otro lado hay que establecer ciertos marcos de referencia para poder delimitar el campo de estudio. Dado que mi interés radica en averiguar si hay un corpus que apoye la denominación de literatura sefardí y mizrahi latinoamericana, he optado por limitarme a los escritores que identifico como tales. 
Chocrón (1961). No todos los de la lista aparecen en la antología de Goldemberg. He agregado a: Esther Cohen, ensayista e investigadora, pero que, según creo, no ha escrito obras de creación; Ricardo Halac, dramaturgo reconocido en Argentina, quien al parecer no ha escrito sobre tema judío; Vicky Nizri, que ha publicado su primera novela (Vida propia) en 2000; Reina Roffé, escritora conocida en la Argentina, sobre todo asociada con la generación de la llamada «guerra sucia», es decir, la que aparece durante la dictadura militar de los años setenta y ochenta; y David Unger, traductor y escritor guatemalteco emigrado a Estados Unidos.

Es necesario hacer algunas precisiones sobre los autores citados. 1) No todos escriben en español; dos o tres de ellos (Perera, Unger y Behar) emigraron a Estados Unidos de pequeños y escriben en inglés. 2) Algunos (Behar, Porzecanski, Shua) son hijos de matrimonios mixtos (sefardí-ashkenazi, mizrahi-ashkenazi), por lo que su experiencia es doble. Y 3) Muñiz se dice descendiente de criptojudíos y se ha reafirmado en su judaísmo tomando lo sefardí como tema central de su obra ${ }^{13}$.

La lista refleja una amplia gama que va desde escritores ampliamente conocidos en sus respectivos países (Isaac Chocrón en Venezuela o Muñiz en México), hasta los «no profesionales» que intentan tan sólo dar testimonio de sus respectivas comunidades. Paralelamente, algunos textos presentan técnicas narrativas o poéticas más simples, mientras que otros marcan pautas experimentales (por ejemplo, la novela La rompiente de Reina Roffé, emblemática de la «nueva» narrativa argentina). En muchos casos, como suele ocurrir con otros grupos migratorios, el elemento biográfico es fundamental (Issac Chocrón, Nissán, Nizri, Perera, etc.).

13 Es posible que por ignorancia haya omitido algunos nombres. Se trata por el momento de una lista provisional y arbitraria que, como es común al tratar de encasillar a escritores, sirve tan sólo como marco de referencia. Cabría quizás añadir las memorias escritas por Teubal (Argentina), DABAH ASKenAzi (México), Botbol HACHUEl (Venezuela) y SEROUSSI (Uruguay), y los documentos de historia oral que se han venido recogiendo en los últimos años en diferentes países latinoamericanos: en México, el Archivo de Historia Oral incluye 152 entrevistas (vid. sus resúmenes en GOJMAN DE BACKAL 1990); para Argentina, se recomienda GUTKOWSKI (1999); para Uruguay, PORZECANSKI (1986); para Brasil, WOLFF (1988); y de Chile vid. las múltiples citas de entrevistas orales en MATUS GonZÁLEZ (1993). En Venezuela, como ya señalé antes, existe el ambicioso proyecto de publicaciones de la colección Biblioteca Popular Sefardí, en donde han aparecido estudios más sistematizados sobre las comunidades sefardíes venezolanas. 
También debo señalar que no se puede desvincular la cultura de los judíos de América Latina de su entorno. Sosnowski (1998 pág. 1121) señala acertadamente que «cada uno de los escritores judíos latinoamericanos opera dentro de fronteras geográficas y/o culturales que lo vinculan directamente con su respectiva literatura nacional».

En términos generales, el modo de abordar la identidad sefardí/mizrahi en la literatura de la que nos ocupamos presenta una doble vertiente ${ }^{14}: 1$ ) la reflexión y el estudio del esplendor de la «edad dorada» de la cultura judía medieval (mediados del siglo X a mediados del XII) durante la época de dominación árabe en la Península Ibérica, y junto con ello la nostalgia de un origen maravilloso y la amargura del exilio y la persecución a través de los siglos; y 2) el mundo sefardí y mizrahi moderno o contemporáneo, con especial interés por temas como migración, adaptación, asimilación, tradiciones y costumbres, etc., así como reafirmación cultural, conciencia de minoría, disputas de identidad, etc. Como en buena parte de la literatura judía, un rasgo que se repite constantemente es la insistencia en la migración y las interdependencias de las comunidades latinoamericanas con las de Israel, Estados Unidos y otros países.

\section{LUCHAR CONTRA EL OLVIDO: EL ESPLENDOR DE LA CULTURA SEFARDÍ}

Como no puede ser menos, la primera vertiente es de destacada importancia para todo sefardí, puesto que en la «edad dorada» medieval está el prestigio cultural que reafirma la conciencia de un origen esplendoroso. Volver a los clásicos de esa época (Yiŝac ibn Jalfun, Šemuel ha-Naguid, Šelomó ibn Gabirol, Mošé ibn 'Eźrá, Yehuda Haleví, Abraham ibn 'Eźrá, Maimónides y los cabalistas del siglo XIII) es una forma de recobrar el orgullo cultural y de poner de relieve que la identidad sefardí cuenta con una gran tradición.

Pero precisamente por ubicarse en el pasado y no en el presente, y por haber tenido que salir forzosamente de España, gran parte de la literatura sefardí está cargada de nostalgia y marcada profundamente por el sentimiento de desarraigo y exilio. A ello hay que agregar el amor y la fidelidad que se guarda hacia la cultura original a través de la preservación de la lengua, las canciones y las costumbres.

\footnotetext{
${ }^{14}$ Voy a centrarme sólo en los textos que versan explícitamente sobre esa identidad sefardí/mizrahi en América Latina.
} 
En ese sentido los escritores sefardíes latinoamericanos no difieren de los de otras partes del mundo. La reflexión y el orgullo acerca de ese pasado glorioso se da, por ejemplo, en el poeta, novelista y crítico argentino Marcos Ricardo Barnatán, quien se ha especializado en temas cabalísticos. Ya sea a través de sus libros analíticos y expositivos acerca de la cábala, en sus poemas evocadores o en sus novelas borgesianas, Barnatán reafirma la gloria que presuponen los hallazgos de la mística judía.

Algo semejante se podría decir de la escritora franco-mexicana Angelina Muñiz. Tanto en su recopilación de literatura sefardí, La lengua florida, como en sus ensayos sobre cábala y en sus ediciones de la obra de Maimónides, Muñiz festeja una larga tradición intentando salvarla del olvido. Precisamente, tal vez sea la lucha contra el olvido el vínculo que sirve de común denominador en la cultura sefardí. Así, atados al pasado y con conciencia del exilio, el ámbito de esta literatura oscila entre la fiesta y la desazón.

La poeta mexicana Myriam Moscona comenta en un texto autobiográfico: «Los abuelos murieron y dejaron una estela de palabras que aún forman parte de mis expresiones espontáneas. El ladino no pasó a formar parte de la poesía que años después empecé a escribir. Creo, sin embargo, que su sentimiento de promesa y expulsión quedó como un aliento echado sobre el vidrio» (en Goldemberg pág. 222). Ese doble ámbito es una condición que varios escritores sefardíes van a tratar de explorar.

En un poema-homenaje al amor de Borges por lo judío-sefardí, Barnatán escribe: «La memoria se disipa. / Las palabras derraman sonidos antiguos / que en la noche descifro. / Hablan de una ciudad que fue mía / de una lengua y una música olvidada. / Sobre mi frente persisten algunas marcas / y entre mis libros sobrevive alguno / que fue tesoro en el alba terrible / de un adolescente urbano. / Atado a ese reclamado paraíso / que la tranquila distancia arrebata / está usted Borges» (en Goldemberg págs. 368-369).

Con la mirada fija en el esplendor anterior, hay un intento por rebasar la condena del vagabundeo en favor de la recreación de la memoria. Uno de los métodos tradicionales entre los sefardíes para lograr este objetivo es el de complacerse en el idioma; percibirlo como la casa o la patria perdida. Lo curioso es que el judeoespañol o ladino aparece muy poco entre los escritores latinoamericanos, salvo los casos muy notorios de Rosa Nissán y más recientemente de Vicky Nizri. 
La paradoja de la migración sefardí a Latinoamérica es que al vivir en países de lengua castellana el judeoespañol perdura sólo en la primera generación, puesto que queda completamente diluido en las ya nacidas en tierras americanas.

El Cuaderno Spinoza (1977) del argentino José Isaacson ilustra la identificación del escritor con un linaje prestigioso aunque simultáneamente desgarrador por la marca del exilio, el aislamiento y la marginación. Se trata de un poema largo, escrito en forma de cartas dirigidas al filósofo sefardí Baruj Spinoza. Desde la «Advertencia» previa (pág. $10)$, Isaacson refiere su genealogía para establecer lazos de afinidad con el filósofo:

Mi tradición familiar quiere que descienda de los servidores del Templo que construyera el hijo de David. Además, por la rama de mi ascendencia materna desciendo de los Madera de Sefarad. Uno de ellos me recordó la erudición de Raimundo, fue López Madera, escritor español del siglo XVIII. Por otro de los Madera -mi bisabuelo-me llamo José.

Y ya en el interior del poema (pág. 94) establece el linaje sefardí como modo de identificarse con Spinoza: «Baruj, / quizá en Orense o en Burgos, / alguna vez / nuestros abuelos cruzaron / sus exilios, / y yo, / junto a este nuevo Jordán / de antiguos mapas / contigo me encuentro». El poeta argentino busca ese parentesco a través de una misma herencia y evidentemente también en la excomunión que sufrió Spinoza de la propia comunidad a la que perteneció.

Lo interesante de la cita es la adaptación de Isaacson a sus propias circunstancias: el nuevo Jordán es una alusión al Río de la Plata (en otra parte del poema, dice: «te llevo a mi Jordán / mi barroso río»). Incluye (entre las págs. 96 y 97) el famoso mapa de Martin Waldseemüller de 1507, en el cual, según Isaacson, se identifica al Río de la Plata como el Jordán ${ }^{15}$, que obviamente alude a la tierra prometida y a la redención. En otra parte del poema se dice que los sefardíes de Amsterdam llamaban a su ciudad la «Nueva Jerusalén». De ese modo el anhelo de Isaacson es el de encontrarse con Spinoza en la tierra

\footnotetext{
${ }^{15}$ Al pie del mapa aparece la siguiente nota: «Fragmento del planisferio de Martín Waldseemüller, autor de una Introducción a la cosmografía (1507), en la cual, por primera vez, se designa con el nombre de América al Nuevo Mundo. El Jordam, señalado en la parte inferior es nuestro Río de la Plata». Vid. al respecto LINDSTROM (1989).
} 
«alegóricamente hablando» de la redención (pág. 192): «A pesar de los tiempos distintos / es posible / que nuestros caminos, / por algún extraño modo, / se entrecrucen / en este lejano Sur / donde tu maestro Menassé / ben Israel / ubicó la tribu perdida».

Mientras que la identificación de Isaacson con Spinoza se fundamenta en el exilio y el prestigio ganado por el filósofo holandés, en The Cross and the Pear Tree el escritor guatemalteco estadounidense Víctor Perera hace una exploración del exilio sefardí a través de un minucioso examen del recorrido genealógico del nombre Pereira («Y si la historia de los judíos ibéricos pudiera resumirse en la experiencia de una sola familia, los Pereiras servirían de la mejor manera» [pág. 74]).

El libro oscila entre ensayo, reportaje, novela, autobiografía, crónica y/o relato de viajes, en el que el autor se legitima al presentar una buena cantidad de personajes ilustres en su recorrido histórico; su investigación es a tal grado extrema que llega a abrumar. El esquema de trabajo consiste en hacer reflexiones acerca de los Pereira en la diáspora y en Israel; los capítulos llevan los nombres de los lugares visitados: Israel, España, Portugal, Amsterdam (Holanda), Francia, Jerusalén, Egipto y Guatemala.

En algunos casos el inicio del relato comienza con el directorio de teléfonos (28 páginas de Pereiras en Portugal, por ejemplo), pero obviamente cada capítulo se centra en personalidades destacadas. Por ejemplo, el caso de Abraham Israel Pereira de Amsterdam, que fue el líder y encargado de excomulgar a Baruj Spinoza de la comunidad judía.

Aunque a lo largo del libro hay alusiones a su familia directa, Perera termina con dos capítulos dedicados al relato autobiográfico de su experiencia en Guatemala y en Estados Unidos, a veces en relación con lo que él considera la mala suerte (o el mal de ojo) que persigue a su familia, centrándose en la tragedia de su hermana. Después de tanto despliegue genealógico, Perera termina curiosamente con un tono melancólico y pesimista: decide conscientemente no tener hijos para que la maldición que los ha marcado no caiga sobre sus descendientes. La maldición parte de su propio bisabuelo, quien en su testamento prohibió a la familia que emigrara de Israel. El castigo se deriva, pues, de la transgresión que significó el deambular por la diáspora. La gloria y el esplendor sefardí termina simbólicamente interrumpién- 
dose en la propia persona que recibe ese legado. La lucha contra el olvido se convierte en una derrota y una amargura que clausura el futuro.

\section{LA AMBIGÜEDAD ENTRE EL MUNDO ATÁVICO Y LA TRANSGRESIÓN}

Utilizo el eslabón de la última parte del libro de Perera para referirme ahora a lo que considero la segunda vertiente de la literatura sefardí: la que se refiere a las comunidades contemporáneas. Obviamente mi esquematización es arbitraria, como lo demuestra el mismo libro de Perera, dado que se trata de un constante vaivén entre el pasado y el presente.

Es un lugar común el afirmar que el esplendor sefardí es un asunto del pasado. Tal vez habría que replantearse esa cuestión pensando que en el siglo XX ha habido escritores sefardíes y mizrahis de primerísima importancia a nivel mundial, como el Premio Nóbel de literatura (1981) Elías Canetti, el gran poeta francés de origen egipcio Edmond Jabès, el filósofo francés de origen argelino Jacques Derrida o en menor medida el novelista sefardí Albert Cohen de familia originaria de Grecia. Lamentablemente la difusión y repercusión de sus obras ha estado en muchos casos limitada a círculos universitarios. Hay una imperiosa necesidad de elaborar una antología mundial de la literatura sefardí/mizrahi con el objeto de obtener una visión más realista de la situación actual.

El exilio de los judíos del Norte de África y de Medio Oriente a lo largo del siglo XX ha incentivado el trabajo de investigación sobre los mismos, aunque su valoración sigue siendo mínima. Mientras que los sefardíes se aferran a una cultura de esplendor, los judíos de esas otras zonas son percibidos como ignorantes y supersticiosos.

Daniel Schroeter hace un agudo análisis de la transición que va de una posición de alta alcurnia espiritual, educativa y religiosa normalmente relacionada con la alta influencia de los sefardíes de la «edad dorada» (siglos X al XIII), a una supuesta era de decadencia. Schroeter intenta mostrar uno de los momentos claves en esa transición: la identificación e invención del concepto «oriental» para aplicarlo a los judíos del Norte de África y Medio Oriente ${ }^{16}$.

${ }^{16}$ Orientalism, de Edward SAID (1978) es el libro más famoso e influyente sobre el tema; sin embargo, Said apenas hace referencia a los judíos. 
El estudio de Schroeter se ilustra con las reflexiones hechas en 1792 sobre los judíos de Marruecos por el judío italiano Samuel Romanelli. Básicamente Romanelli une la percepción que tiene de los musulmanes con la de los judíos, asumiendo que los últimos no han tenido opciones claras de desarrollo cultural y educativo, dado que, según él, el contexto y la opresión de la sociedad islámica los mantiene marginados frente al progreso, la ciencia y el conocimiento (Schroeter pág. 184):

La falta de libros y noticias arrastra sus corazones en el lodo de la ignorancia y la superstición. Tienden a ver todo lo nuevo y las cosas misteriosas y desconocidas como milagros. Las ciencias son demasiado elevadas para ellos. Su ignorancia es el colmo, ya que dicen que muchas víctimas han sido arrojadas a los pozos de la herejía y el ateísmo por la ciencia. La luz del conocimiento no brilla sobre ellos, ni siquiera ha alcanzado a erradicar sus caídas morales y sus vanidades inmaduras. Un velo de fe oscurantista corrompe sus corazones y enceguece sus ojos.

Romanelli sigue los modelos de la Ilustración europea para mostrar a los países del Norte de África y Medio Oriente como ignorantes, irracionales y supersticiosos, y por lo tanto incapaces del desarrollo del conocimiento científico. Como dice Schroeter (pág. 184), «la Ilustración usa el Islam ... para legitimar la superioridad del racionalismo de la civilización europea en la era del desarrollo nacionalista». Esa es la base ideológica que justifica el imperialismo europeo en el Norte de África y Medio Oriente desde que Napoleón invade Egipto a finales del siglo XVIII.

La ironía de la actitud de Romanelli radica en que hasta ese momento a los sefardíes (definidos de un modo amplio que incluye a los mizrahis) se les consideraba tanto por judíos como por no judíos como la nobleza y la élite cultural del mundo judío. Algunos historiadores, por ejemplo, han argüido que el declive español y los cambios de orden económico que llevaron al apogeo a países como Holanda, son consecuencia del exilio sefardí y de su contribución al desarrollo de los Países Bajos. La culminación de tal idea es la tesis de Werner Sombart (1911), quien atribuye a los sefardíes el cambio y la entrada del capitalismo en el orden mundial.

Curiosamente, al obtener el derecho de ciudadanía después de la Revolución Francesa, los judíos comenzaron a identificarse con las 
naciones-Estado en las que vivían, por lo que las alianzas judías que traspasaban límites fronterizos y lingüísticos fueron diluyéndose de tal forma que la emancipación produjo una nueva dicotomía: norte/sur, occidente/oriente. El concepto del judío oriental surge a partir de ese momento. La visión del judío occidental de que había que mejorar la educación de sus correligionarios de Oriente se ve claramente en la fundación de la Alliance Israelite Universelle en 1860, que estableció una extensa red de escuelas en el Norte de África y en Medio Oriente con el propósito de educar e inculcar la civilización occidental. Schroeter llega incluso a afirmar que los judíos occidentales son los que «inventan» o desarrollan el tópico de la «edad dorada» de la civilización judeo-árabe en España.

También es interesante que al mismo tiempo se desarrolle entre los judíos alemanes un desdén hacia Europa Oriental, que prefiguró la palabra Ostjude «judío oriental» para referirse a los que habitaban esa zona como retrasados que mantenían costumbres de superstición e ignorancia. Me gustaría ilustrar ese concepto del orientalismo con los párrafos juguetones y sarcásticos de la escritora argentina Ana María Shua (1993 págs. 14-15):

Los judíos ... somos todos aristócratas: como los irlandeses. Y dentro de esta aristocracia, cuanto más al oeste, más fine mensh. Mi abuelo libanés, por ejemplo, se jactaba del abolengo de su sangre por ser de Beirut, es decir, superior a los de Damasco y a los de la vil Alepo, esos deleznables degustadores del quippe jalabíe. Y del lado de mi mamá, mis abuelos litvakes se consideran naturalmente superiores a los árabes. Pero siempre con el criterio de que la raza mejora hacia el oeste, todos los judíos eslavos (entre los que hay también jerarquías que distinguen a los rusos de los poilishes de los bezaraber de los litvakes) se saben inferiores a los iekes, los judíos alemanes. Con este criterio, la más refinada nobleza les corresponde a los judíos italianos, franceses o ingleses.

En este punto recuerdo un curioso detalle de la biografía de Kafka escrita por su amigo Max Brod, en que relata el choque emocional y el interés que sintió Kafka cuando tuvo oportunidad de conocer a esos extraños «judíos orientales», con sus vestimentas típicas, sus anticuadas costumbres, su peculiar dialecto. Kafka y Brod, habitantes de la sofisticada ciudad de Praga, llamaban «judíos orientales» a los provenientes de los shteitls, las aldeas judías en Rusia y en Polonia.

En general, del esplendor de la cultura sefardí, extendida no sólo en el Norte de África y Medio Oriente, sino también en diferentes partes 
de Europa, se pasa a una división entre occidentales y orientales, mayormente dominada por los países de origen y sus respectivos desarrollos económico-culturales. La marginación, estereotipo y percepción exótica del llamado Tercer Mundo afecta a los judíos que habitan esas regiones. Tal división política ha creado indudablemente una tensión al emerger el Estado de Israel, ya que los llamados mizrahis (aunque no son una minoría) son los que constituyen el grupo dominado, de bajos recursos económicos y con poco acceso a los centros de poder ${ }^{17}$.

A pesar de que en América Latina los mizrahis no han pasado por tan difíciles circunstancias, me interesa examinar el eco de esa disputa en algunos textos. En primer lugar, hay una resistencia por parte de los sefardíes a ser confundidos con los mizrahis u orientales. Por ejemplo, Perera (pág. 117) dice que su bisabuelo firmó su testamento con las letras en hebreo sámej y tet, iniciales de «sefardí tahor», o «verdadero sefardí», implicando su distancia tanto con respecto a los judíos orientales como a los conversos.

Algo semejante ocurre con los libros de la escritora mexicana Rosa Nissán. En ellos aparece el mundo sefardí contemporáneo de México a través de la historia de una niña (y después mujer) de familia turca. Aunque desde el inicio de la primera novela la tensión se centra en establecer un modo distinto de percibir la mexicanidad a través de la inclusión de la variante judía, hay también alusiones claras a las dife-

17 La experiencia de los mizrahíes en Israel ha sido muy distinta de la de sus paisanos en Estados Unidos y América Latina. Por lo general, los emigrantes a América Latina llegaron en condiciones muy desfavorables, pero poco a poco su situación económica mejoró considerablemente. Es notable ese contraste, por ejemplo, en el libro de memorias de KALACH, nacido en Damasco y emigrado a Israel. Allí (pág. 180) relata la reacción de su primo que venía de México al verlo como repartidor de pan: «Él me miró conmovido y sus ojos se llenaron de lágrimas. 'No puedo creer lo que mis ojos están viendo, que éste es el modo en que mi primo se gana la vida', dijo ... mi primo era entonces un gran industrialista y nunca se imaginó la situación en la que sus familiares tenían que trabajar tan duro para su sustento». SHOHAT (pág. 14) afirma, por otra parte, que «para los mizrahíes, Israel no ha sido propicio para el éxito. Muchas familias que tenían vidas prósperas en Egipto, Irán, Iraq, Marruecos o Túnez vieron un declive en Israel; sus hijos se convirtieron en drogadictos, prostitutas, criminales. Mientras que la mayoría de los judíos en prisión son de origen no ashkenazi, la mayoría en la universidad (tanto profesores como estudiantes) son ashkenazi». Se podría pensar que el concepto de subalternidad es aplicable a los mizrahíes de Israel; sin embargo, tal vez a los mizrahíes de América Latina sería preferible concebirlos bajo el concepto de lo «menor» (según la concepción de DeleuZE - GuATTARI Kafka), como ya se señaló antes. 
rencias entre los distintos grupos de inmigrantes judíos. Sobre todo se subraya la distinción entre sefardíes y judíos árabes (en México predominan los de Siria, separados a su vez por antagonismo de origen en dos comunidades: los shami de Damasco y los jalebí de Alepo).

La madre de la protagonista dice de ellos (1992 pág. 27): «Son atrasados y pesgados ... a tu tía nunca la dejaron salir sola, traían maestro a la casa ... ¡ Uf!, ni amigas le desharon tener». El matrimonio entre la tía y un miembro de la comunidad árabe sirve para ilustrar las diferencias: los sirios son más religiosos y se mantienen fieles a sus costumbres. Las disputas se reproducen a lo largo de las dos novelas de la autora, expresando las mutuas recriminaciones. El tío opina (1992 págs. 36-37) que «en el knis [sinagoga] donde él va, la oración se termina más tarde, porque es más completa. Lo dice recalcando que su judaísmo es superior al nuestro, porque según él no llevamos la religión como debe ser, y en shabat subimos en coche ... dice que cómo es posible que haya micrófono en nuestro templo, que es utilizar electricidad y eso es pecado, y que los rabinos turcos son religiosos a su conveniencia».

Es posible que un lector no informado no distinga claramente las diferencias de cada una de las comunidades judías de México, pero sí es evidente que la convivencia en una misma ciudad produce matrimonios entre miembros de los diversos grupos. La novela Novia que te vea acaba precisamente con la boda de la protagonista con Lalo, de padre turco y madre siria. Y curiosamente las diferencias en vez de resolver el conflicto lo aumentan y en ocasiones propician no sólo el divorcio, sino también la separación de la protagonista de la comunidad judía y su integración y asimilación en la sociedad no judía.

Es interesante además que esa diferencia entre sefardíes y judíos árabes haya tenido que reformularse en la adaptación de la novela al cine, en la película producida y dirigida por Guita Schyfter, con argumento de la propia Schyfter, Rosa Nissán y Hugo Hiriart, escrito por el último. La tensión dramática está planteada ahora a través del diálogo de dos amigas, una sefardí y otra ashkenazi. Dos escenas aluden claramente a las diferencias entre las dos comunidades; en la primera, ante el deseo de la protagonista de estudiar pintura la madre sefardí y sus amigas se quejan de que la amiga ashkenazi (Rifke Groman) es la que le «mete ideas en la cabeza». Los ashkenazis son los que transgreden la tradición: «las idishicas son todas atavanadas [tras- 
tornadas]», dice una de las mujeres. La madre de Rifke, por otra parte, señala en la escena inmediatamente posterior que «los sefaraditas son atrasados, schlepers [cargadores], son ignorantes», aunque el padre los defienda continuando la frase de modo irónico: «ignorantes como Maimónides y Baruj Spinoza», ante lo cual la madre reacciona reduciendo la sabiduría sefardí a un momento del pasado, ajeno a las circunstancias del presente: «eso fue hace mucho tiempo».

Un aspecto común en varios de los textos escritos por sefardíes o mizrahis es que los autores se han visto en la necesidad de distanciarse de las comunidades a las que pertenecen para criticarlas. En el caso de Nissán está muy claro que la rebelión femenina de la protagonista es una reacción frente al sistema patriarcal imperante no sólo entre los judíos árabes, sino también entre los sefardíes.

Ya en la segunda novela, Hisho que te nazca, la madre de la protagonista no ataca a su yerno por ser árabe, sino que lo defiende por haber adquirido una mejor posición económica y ante el riesgo de que su hija se asimile a la sociedad no judía: «¡Atavanada estás! ¡Cómo vas a deshar este modo de marido! Tienes casa, coche, dos jismichías [sirvientas], un hombre, todo el mundo te respeta, vives como una reina. Anda, boba no seas, tú hazme caso, arrecóyete otra vez, te vas a meter en velás [problemas]. Velás con parás [dinero]. Él va a tomar una jovencica soltera y hasta dote le van a dar; otra va a gozar de lo bueno que ganó contigo, porque cuando tú lo tomates, rico no era» (1996 pág. 141).

La paradoja en los libros de Nissán es que si bien se rebela frente a la tradición patriarcal del judaísmo sefardí, es precisamente ese mundo el que da sentido y atractivo a su literatura. Sin el rico elemento sefardí, Hisho que te nazca sería una novela trillada del feminismo, ya que esa rebelión no es novedosa en el ámbito literario hispanoamericano. Gracias al lenguaje judeoespañol y al retrato de las costumbres y formas de la vida cotidiana de los sefardíes, las novelas de Nissán son una contribución importante para la comprensión de un México más diverso y multicultural.

Pero Nissán no es la única mujer en debatir la doble actitud hacia la cultura patriarcal sefardí y judía, en general. Liliana Mizrahi ha expresado el dilema del siguiente modo (1990 págs. 19-21):

Ser una escritora judía y sefaradí es una experiencia compleja ... Mi necesidad de ser una mujer transgresora se realimenta todos los 


\begin{abstract}
días, cada mañana, cuando los varones rezan: «Gracias, Dios mío, por no haberme hecho mujer» ... La sefaradí, la ancestral que me habita es también parte de mi judaísmo que me obliga a perpetuarme en un modelo estático. Lucho para poder salvarme como judía de la judía que me atormenta. Aquella que cree que para ser hay que repetir. La judía cristalizada. La que dice: soy el eco de un eco de un eco ... Esta pugna interna entre la judía ancestral y la transgresora explicita no sólo la lucha entre dos modos de relacionarme con la tradición judía, sino también entre dos aspectos del judaísmo.
\end{abstract}

Mizrahi comprende que su identidad judía depende en alto grado de preservar la tradición («para ser hay que repetir», «soy el eco de un eco de un eco»). Pero evidentemente no puede evitar reaccionar frente a las condiciones de esa tradición que marginan a la mujer. De ahí que el conflicto radique en cómo rebelarse frente al sistema patriarcal judío, sin dejar de pertenecer a esa tradición. En un ensayo anterior Mizrahi equipara lo sefardí a lo ancestral (1987 págs. 69-70):

Soy de origen sefardí. Los sefardíes nos hemos preservado en un idioma que no conoce las transformaciones del tiempo: el ladino o español antiguo. Y preservamos en ese idioma enseñanzas éticas que han mantenido su valor a lo largo de la historia. Idioma atado a lo ancestral y cargado de mandatos atávicos. Pertenecer a una familia de origen oriental creo que es lo que me impulsa a indagar y cuestionar el lugar de la mujer en la historia de la cultura ... Es a través de la palabra que intento una síntesis de lo que siento que vive en mí como oriente y occidente.

Aunque los investigadores han desmitificado la idea de que el judeoespañol jamás ha evolucionado ${ }^{18}$, es interesante la asociación entre lo sefardí-ancestral y el Oriente. En ese sentido Mizrahi percibe la dicotomía Oriente-Occidente como una disputa entre lo antiguo y lo moderno, lo atávico y lo transgresor.

Quisiera ahora examinar cómo esa pugna interna de Mizrahi encuentra expresión en la novela fundacional del sefardí contemporáneo: Rómpase en caso de incendio (1975), del venezolano Isaac Chocrón. En esta novela un hombre llamado Daniel Benabel decide viajar a España y a Marruecos después de haber perdido a su padre, esposa e hijo, a causa de un terremoto en Venezuela. La novela consiste en las cartas que escribe Benabel, donde va explorando su identidad y orígenes.

${ }^{18}$ Véase DíAZ-MAS págs. 103-129. 
La extensa gama de elementos expuestos en la novela me impide hacerle justicia en el contexto de un artículo general sobre literatura sefardí. Quisiera simplemente hacer unos comentarios acerca de cómo el personaje se sale de su ambiente para poder observarlo en la distancia; es decir, no sólo se plantea como un viaje a los orígenes familiares, sino como una crítica del entorno al que pertenecía. Véanse, como ejemplo, las observaciones acerca de lo que el protagonista percibe como cerrazón e inflexibilidad de la comunidad sefardí venezolana. Al referirse a sí mismo como el único judío del mundo que se hace pasar por moro, dice (pág. 280):

... el doctor Benchetrit supone que la más grande «mizvah» que puede hacer es regenerarme. Tú no sabes lo que quiere decir «mizvah»; es como cumplir una buena acción y los hebreos, con tal de hacerlas, a veces son capaces de triturar a cualquiera. El problema de ser hebreo, mi querida Sarita [se trata de una mujer negra que trabajaba con la familia como cocinera] ... es que a uno se le exige formar parte de la Comunidad, comportarse según sus principios y costumbres. Quien se salga de la raya, y la raya es en realidad un círculo, debe regresar lo más pronto posible por las buenas o por las malas, vivo o muerto. En vez de ignorarlo, marginarlo o sacarlo de la Comunidad, la mizvah es tratar de domarlo para que siga perteneciendo a la congregación, aun cuando sea un miembro no deseado. Los judíos consideran que ser judío no es sencillamente practicar la religión sino que es un compromiso surgido al nacer y que no se puede cancelar. Ser judío es estar marcado.

Ese rasgo definitorio del grupo plantea el doble juego de pertenecer y no pertenecer a la sociedad mayor. En la novela se describe, por ejemplo, la invención de la jaquetía, lengua de los sefardíes del norte de Marruecos en que se combinan el español, el francés y el árabe, salpicada con palabras en hebreo (pág. 222): «iAh, los hebreos, los míos! ¡Qué sagaces! Sólo a ellos se les ocurrió combinar las lenguas para entenderse sin que los demás los entiendan». Lo curioso de esta invención es que el grupo se mantiene al margen y, sin embargo, ha incorporado los elementos de las culturas que lo circundan.

La dicotomía Oriente-Occidente está planteada, como en Liliana Mizrahi, entre lo antiguo y lo moderno. Hay mucha más ambigüedad en la novela de Chocrón, dado que el personaje va modificando sus observaciones a medida que avanza el tiempo y se integra y se desarraiga de los lugares visitados. El contraste también está planteado en 
términos económicos. Por ejemplo, Caracas funciona en la novela como el emblema del materialismo occidental en el contexto de la repentina riqueza de los años setenta derivada de la explotación de los pozos de petróleo, mientras que Tánger se ve inmersa en la pobreza y la superstición (pág. 203):

Desde aquí pienso que todo nuestro malestar colectivo proviene de nuestra suerte occidental. Somos un pueblo que se ganó el primer premio de la lotería, el gran gordo del siglo. Nuestra repentina riqueza y su incrementado valor acabó con la conciencia que poseíamos ... Cuando digo conciencia, me refiero a valores, esfuerzos y aspiraciones. Todo eso se acabó con la riqueza que el petróleo trajo al fisco ... Cuando yo veo la inmensa pobreza que ahora me rodea, cuando parece un milagro la mera supervivencia de la mayoría de los marroquíes, entiendo su fanatismo religioso ... El contraste entre la resignación marroquí y la despreocupación venezolana ... es un contraste muy profundo y aterrador. Para alejar la mala suerte, aquí se cree en una mano extendida: la Jamsa. Venden estas jamsas por todas partes para ser usadas como amuletos. Cuando alguien se entera de una mala noticia o tiene una premonición oscura, abre una mano y exclama: ¡Jamsa! ¡Jamsa!

Si al llegar a Tánger Benabel siente que puede pasar por «moro»e integrarse en la ciudad sin mayores problemas, hacia el final de la novela se da cuenta de que su asimilación sólo ha sido un engaño (pág. 311): «aunque me quede mil años seguiré siendo un extranjero», y que lo único que le queda es reencontrar la ciudad y el país al que pertenece. Sin embargo, irónicamente, antes de emprender el viaje de vuelta Benabel muere apedreado por unos delincuentes árabes. La novela cierra así el círculo con el que se abre. El recorrido termina sin la posibilidad de contemplar qué pasará con Benabel una vez vuelto a Caracas.

Hay además una homosexualidad latente en la novela que culmina de algún modo con la descripción de un travestí judío de Tánger que ha venido a menos. La sentencia del personaje (Momy) termina por ser categórica (pág. 286): «Judío es judío, mi rey, donde quiera que vayas. Aunque te escondas, te descubren. Ser judío y además ser maricón significa pertenecer a las sectas públicas más poderosas de la tierra».

Curiosamente, Rómpase en caso de incendio se escribe desde el lugar de los orígenes, pero situado en un presente que delata una 
comunidad judía (la de Marruecos) en plena decadencia; Benabel subraya en varias ocasiones que sólo se han quedado los viejos y los pobres; el mundo sefardí se encuentra desprovisto de la riqueza de la que había gozado. En su visita a Melilla, por ejemplo, Benabel constantemente contrasta las «viejas» costumbres y supersticiones de esa comunidad con la modernidad en la que viven los judíos de Caracas.

No obstante, la novela quiere ser una celebración de la hibridez cultural. Quizá su parte más apasionante sea el descubrimiento y estancia del personaje en Tánger. Allí, Benabel se ve como una especie de camaleón, feliz con la posibilidad de hacerse pasar por miembro de cualquiera de los tres grupos de la ciudad musulmanes, judíos y cristianos (págs. 212-213): «Soy la conjugación de las tres razas y voy de una a la otra, aceptado en las tres, aunque te confieso que usar babuchas en vez de zapatos no está bien visto por los europeos y los hebreos». Pero ello implica - a la luz del conflicto árabe-israelí, aunque éste no figura en el libro- una especie de disidencia al subrayar su entusiasmo por la sensualidad árabe.

En otro lugar define su identidad casi como contrapeso de la ashkenazi (págs. 229-230):

\begin{abstract}
¿Así que te burlas de que a un judío como yo le guste vivir entre los moros? Olvidas que soy judío sefardita: tan africano, tan español y tan venezolano que los yiddish de Brooklyn me considerarían hereje. Tuve que venir aquí para comprender de veras este pastel de herencias. Recuerdo que en Caracas, cuando niño, me desagradaban los cantos en la Sinagoga porque, en vez de tener una melodía redonda y pegajosa, parecían gritos y lamentaciones discordes. Ahora comprendo que nosotros rezamos con el canto del idioma árabe en nuestros oídos.
\end{abstract}

Otras dos novelas hacen alusiones al mundo árabe ancestral: Perfumes de Cartago, de Teresa Porzecanski, y La rompiente, de Reina Roffé. Son otros dos modos de revelar una herencia, cuyo examen dejo para otro estudio.

Queda, sin embargo, mucho camino por recorrer. Aunque este artículo demuestra que en América Latina existe realmente una literatura sefardí/mizrahi, también hay que reconocer que no se han explorado en el terreno expresivo todas las posibles conexiones interculturales del entramado de esas comunidades. Las condiciones tanto internas como externas son propicias para que emerjan aún más escritores. El futuro parece prometedor. 


\section{BIBLIOGRAFÍA}

Agosín, Marjorie (ed.). The Alchemists: Jewish Women Writers of Latin America. Fredonia, New York: White Pine Press, 1995.

-. Passion, memory, identity. Alburquerque: University of Mexico Press, 1999.

-. Jewish Women Writers of Latin America. New York: Feminist Press, 1997.

-. The House of Memory: Stories by Jewish Women Writers of Latin America. New York: Feminist Press at the City University of New York, 1999.

AIZENBERG, Edna. "Sephardim and Neo-Sephardim in Latin American Literature», The Sephardic Scholar 4 (1979-1982) págs. 125-132.

—. «Las peripecias de una metáfora: el sefaradismo literario judeoargentino», Noah (Jerusalem) 7-8 (1992) págs. 54-59.

AlCalay, Ammiel. After Jews and Arabs: Remaking Levantine Culture. Minneapolis: University of Minnesota Press, 1993.

-. Keys to the Garden: New Israeli Writing. San Francisco: City Lights Books, 1996.

-. Memories of our Future: Selected Essays 1982-1999. San Francisco: City Lights Books, 1999.

BARNATÁN, Marcos Ricardo. El laberinto de Sión. Barcelona: Barral Editores, 1971.

BOKSER DE LIWERANT, Judit (coor.). Imágenes de un encuentro: la presencia judía en México durante la primera mitad del siglo XX. México: UNAM, Tribuna Israelita ..., 1992.

- y Alicia GOJMAN DE BACKAL (eds.). Encuentro y alteridad: Vida y cultura judía en América Latina. México: Fondo de Cultura Económica, 1999.

Botbol HaChUel, Abraham. El desván de los recuerdos: Cuadros de una judería marroquí. Caracas: Centro de Estudios Sefardíes de Caracas, Biblioteca Popular Sefardí vol. 6, 1989.

CARCIENTE, Jacob y Agnes CARCIENTE. «Sabía usted que... Mil y una curiosidades acerca de la religión, historia, cultura, costumbres y tradiciones judías. Caracas: Centro de Estudios Sefardíes de Caracas, Biblioteca Popular Sefardí vol. 5, 1987.

CHIRA, Robert. From Aleppo to America: The Story of Two Families. New York: Rivercross Publishing, 1994.

ChOCRÓN, Isaac. Rómpase en caso de incendio. Caracas: Monte Ávila Editores, 1975.

DABBAH AsKenAZI, Isaac. Esperanza y realidad: Raíces de la comunidad judía de Alepo de México, Fundación de la Sociedad de Beneficiencia «Sedaka y Marpe». México: Sedaka y Marpe, 1982.

DAYÁN DE MizRACHI, Selly y Nadhji ARJONA. La saga de los sefarditas: del Medio Oriente a Panamá. Panamá: Sociedad Israelita de Beneficiencia Shevet Ahim, 1986.

Deleuze, Gilles y Félix GuATTARI. Kafka: Pour une littérature mineure. Paris: Éditions de Minuit, 1975. 
Della Pergola, Sergio. «Demographic Trends of Latin American Jewry», en LAIKIN ELKIN - MERKX págs. 85-133.

DIANTONIO, Robert y Nora GLICKMAN (eds.), Tradition and Innovation: Reflections on Latin American Jewish Writing. Albany: State University of New York Press, 1993.

DíAZ-MAS, Paloma. Los sefardíes: Historia, lengua y cultura. Barcelona: Ríopiedras Ediciones, 1997.

FEIERSTEIN, Ricardo. Cuentos judios latinoamericanos. Buenos Aires: AMIA, 1990.

FINZI, Patricia, Eliahu TOKER y Marcos FAERMAN (eds.). El imaginario judio en la literatura de América Latina. San Pablo, Brasil: Grupo Editorial Shalom, 1990.

GERBER, Jane S. The Jews of Spain: A History of the Sephardic Experience. New York: Free Press, 1994.

GoJMAn DE BACKAL, Alicia (coor.), Testimonios de Historia Oral: Judíos en México. México: Asociación Mexicana de Amigos de la Universidad Hebrea de Jerusalén, 1990.

Gojman Goldberg, Alicia. Los conversos en la Nueva España. México: Universidad Nacional Autónoma de México, 1984.

GoldEMBERG, Isaac (comp.). El gran libro de América judía. San Juan: Editorial de la Universidad de Puerto Rico, 1998.

GuTKowski, Hélène. Érase una vez... Sefarad: Los sefaradies del Mediterráneo, Su historia - su cultura, 1880-1950 - Testimonios. Buenos Aires: Editorial Lumen, 1999.

Hamui de Halabe, Liz (coor.). Los judios de Alepo en México. México: Maguen David, 1989.

ISAACSON, José. Cuaderno Spinoza. Buenos Aires: Ediciones Marymar, 1977.

KALACH, Yosef. De Damasco a Jerusalén, trad. del hebreo de Esther COHEN TARRAB. Jerusalén: Nathan Roi, 2000.

KALECHOFSKY, Robert y Roberta (eds.). Echad: An Anthology of Latin American Jewish Writings. Marblehead, Mass.: Micah Publications, 1980.

LAIKIN ELKIN, Judith. Jews of the Latin American Republics. Chapel Hill: The University of North Carolina Press, 1980.

- y Gilbert W. MERKX (eds.). The Jewish Presence in Latin America. Boston: Allen \& Unwin, 1987.

LINDSTROM, Naomi. «José Isaacson: An Open Letter to Spinoza», en Jewish Issues in Argentine Literature: From Gerchunoff to Szichman (Columbia: University of Missouri Press, 1989) págs. 113-129.

LOCKHART, Darrell B. (ed.). Jewish Writers of Latin America: A Dictionary. New York: Garland Publishing, 1997.

MATUS GONZÁLEZ, Mario. Tradición y adaptación: Vivencia de los sefaradíes en Chile. Santiago de Chile: Universidad de Chile, Comunidad Israelita Sefaradí de Chile, 1993. 
METER, Alejandro (ed.). Literatura judía en América Latina. Vol. especial de la Revista Iberoamericana 191 (abr.-jun. 2000).

MirelmAN, Victor A. «Sephardic Immigration to Argentina prior to the Nazi period», en LAIKIN ELKIN - MERKX (eds.) págs. 13-32.

MIZRAHI, Liliana. La mujer transgresora: Acerca del cambio y la ambivalencia. Buenos Aires: Grupo Editor Latinoamericano, 1987.

- Las mujeres y la culpa: Herederas de una moral inquisidora. Buenos Aires: Grupo Editor Latinoamericano, 1990.

-. Hembras del ave del paraíso [Poesía]. Buenos Aires: Grupo Editor Latinoamericano, 1996.

NES-El (Arueste), Moshe. Historia de la comunidad israelita sefaradí de Chile. Santiago de Chile: Editorial Nascimento, 1984.

Nissán, Rosa. Novia que te vea. México: Editorial Planeta, 1992.

-. Hisho que te nazca. México: Plaza y Janés, 1996.

-. Las tierras prometidas: Crónica de un viaje a Israel. México: Plaza y Janés, 1997.

NizRI, Vicky. Vida propia. México: Miguel Ángel Porrúa, El Pirul, 2000.

Perera, Víctor. Rites: A Guatemalan Boyhood. 1ª ed. 1985. San Francisco: Mercury House, 1994.

-. The Cross and the Pear Tree: A Sephardic Journey. Berkeley: University of California Press, 1995.

PORZECANSKI, Teresa. Historias de vida de inmigrantes judios al Uruguay. Montevideo: Kehilá, Comunidad Israelita del Uruguay, 1986.

-. Perfumes de Cartago. Montevideo: Ediciones Trilce, 1996.

RofFÉ, Reina. La rompiente. Buenos Aires: Puntosur Editores, 1987.

RUBEL, Iaacov (coor.). Presencia sefaradí en la Argentina. Buenos Aires: Centro Educativo Sefaradí para Latinoamérica, 1992.

Sadow, Stephen A. (ed.). King David's Harp. Autobiographical Essays by Jewish Latin American Writers. Albuquerque: University of New Mexico Press, 1999.

SAID, Edward. Orientalism. New York: Pantheon Books, 1978.

SCHROETER, Daniel J. «Orientalism and the Jews of the Mediterranean», Journal of Mediterranean Studies 4/2 (1994) págs. 183-196.

SENKMAN, Leonardo. «Entrevista a Isaac Chocrón», Noah 1/1 (1987) págs. 79-82.

SEROUSSI, Elías. Memorias de mi comunidad. Montevideo (edición del autor), 1979.

SHOHAT, Ella. «The Invention of the Mizrahim», Journal of Palestine Studies 29/1 (Autumn 1999) págs. 5-20.

SHUA, Ana María. Risas y emociones de la cocina judía. Buenos Aires: Grupo Editorial Shalom, 1993.

SOMBART, Werner. Die Juden und das Wirtschaftsleben. Leipzig: Duncker \& Humblot, 1911. 
SosNowsKI, Saúl. «Los escritores judíos de América Latina: un puente hacia la historia», en GOLDEMBERG págs. 1101-1122. Originalmente en Coloquio 12, 1984.

-. «Latin American-Jewish Writers: Protecting the Hyphen», en LAIKIN ELKIN - MERKX págs. 297-307.

-. «Clipper, de Isaac Chocrón: salida internacional», en Ensayos sobre judaísmo latinoamericano (Buenos Aires: Milá, 1990) págs. 417-424.

STAVANS, Ilan (ed.). Tropical Synagogues: Short stories by Jewish-Latin American Writers. New York: Holmes \& Meier, 1994.

Teubal, Nissim. El inmigrante, de Alepo a Buenos Aires. Buenos Aires (edición del autor), 1953.

WOLFF, Egon y Frida (eds.). Depoimentos: Um perfil da coletividade judaica brasileira. Recordações gravadas em setenta entrevistas. Rio de Janeiro: Erca Editora e Gráfica, 1988.

ZENNER, Walter P. A Global Community: The Jews from Aleppo, Syria. Detroit: Wayne State University Press, 2000.

\section{RESUMEN}

Este es el primer artículo que intenta trazar un panorama de la literatura sefardí/mizrahi en América Latina. Tras una información básica sobre la migración de esos grupos judíos a finales del siglo XIX y principios del XX, se identifica a más de veinte escritores y se plantean dos modos de acercamiento a la identidad sefardí/mizrahi: 1) la reflexión y estudio del esplendor de la «edad dorada» de la cultura judía medieval; y 2) vivencias de los sefardíes y mizrahis contemporáneos. Finalmente, se considera la novela Rómpase en caso de incendio, de Isaac Chocrón, como el texto fundacional de la literatura sefardí/mizrahi contemporánea en América Latina.

\section{SUMMARY}

This is the first article that attempts to trace a panoramic view of Sephardi/Mizrahi literature in Latin America. It starts by giving basic information about the migration of these Jewish groups at the end of the $19^{\text {th }}$ and beginning of the $20^{\text {th }}$ century. Later, it identifies more than twenty writers, and establishes two ways to approach Sephardi/Mizrahi identity: 1) Reflection and study of the splendor of the «Golden Age» of Medieval Jewish culture in the Iberian Peninsula; and 2) representations of contemporary Sephardim and Mizrahim. Finally, the article proposes Isaac Chocrón's novel, Rómpase en caso de incendio, as the foundational text for contemporary Sephardi/Mizrahi literature in Latin America. 